\title{
Nurturing and development of rural areas in Sichuan minority sports performance industry to explore the next experience economy concept
}

\author{
Suqiong Feng ${ }^{1, a}$, Ye Yang ${ }^{2, b}$ \\ ${ }^{1}$ College of arts and sports, Sichuan Agricultural University, Ya'an, 625014, China \\ ${ }^{2}$ Department of physical education, Yi Bing College, Yi Bing, 644000, China \\ fengsuqiong123@163.com
}

Keywords: Experience Economy, Minorities, New rural construction, Sports performance industry, Foster the development of.

\begin{abstract}
In this study, based on the "Experience Economy" research perspective, the use of literature, questionnaire, field interviews and other research methods, dig Experience Features "experience economy" concept under exploratory put forward the "experience economy" experience under the concept of product design ideas; from the "experience economy" concept, the development of rural areas, the plight of Minority sports performance industries analyzed, constructive made the "experience economy" concept in rural areas Minority Sports Shows nurture and develop the path the industry for Sports Industry Development in Minority Areas in Sichuan Province to lay a theoretical foundation.
\end{abstract}

\section{Introduction}

The party's "The 16th National Congress of the CPC " proposed building a new socialist countryside, "National Economic and Social Development Five-Year Development Plan (draft)", the re-building a new socialist countryside clearly stated strategic goals, marking the focus of the country's economic development will gradually toward the development of rural areas lagging behind. Sichuan Province is famous at home and abroad Province of Ethnic Culture, Native peoples 14 to Tibetan, Yi, Qiang mainly large minority population, is the second largest Tibetan, the largest and the only Qiang Yi ghetto neighborhoods .Sports performance industry as a minority compatriots ingenuity to create a collection of cultural and sports activities, even in the knowledge explosion, cross-flow of information, entertainment overwhelming today, but also its unique charm, survival in the festival culture, present in the majority of limb above the people, set a negative culture from traditional folk to the stage, because it is the guardian of the national culture of artistic roots. Sichuan minority rural area sports performance style very alien and exotic features, resources are very rich, how to use a variety of resources and advantages of the full development of the rural areas, Sichuan minority sport performance market, it has played a leading role in the sports performance industry, inheritance colorful, distinctive ethnic performances and traditional sports culture in rural areas of Sichuan Province, and create greater economic benefits for the people, has become an urgent need to address the issue.

\section{An "experience economy" connotation and characteristics}

"Experience economy" connotation. Experience economy is opposed to "non-experience economy" and put forward; the experience economy mainly refers to non-product economy, commodity economy and the service economy.

"Experience economy" feature. Agricultural economy experienced a "land " for the carrier , after the industrial economy to the " goods " as the main source of profits, and the service economy "service " for the trading platform , "experience economy" is being advanced with great and market development advantages, become a higher level of economic shape of the current economic development of various economic forms cross wave update. Experience Economy is to provide economic goods, in order to create a personalized experience of living and commercial profit, to 
emphasize feelings of customers, in order to meet people's emotional needs and self-actualization needs as the primary goal of an economic form [1]. As the economy changes and the changes provide physical economy, experience economy has become an inevitable trend of social and economic development, but also the inevitable product of information technology, network technology development.

"Experience economy" feature. In theory, the experience economy is generated on top of a traditional economy, but a higher level of economic form, it is still the same as the traditional economic patterns and the carrier through the material basis to reflect, and to adhere to the traditional economy, but with other economic forms, compared with distinguished from " nonexperience economy," the salient features. First, significant experience and personalization features. Experience Economy products from the beginning of Hollywood, Disney 's attempt to spread to tourism, entertainment, leisure industry, and then penetrate into the transportation industry, commerce, healthcare, apparel and other industries, and its product has been welcomed by customers, no not because consumer "product" as a process, so that consumers long-term preservation of the process of "experience" feeling. So their experience and personality characteristics have to be the customer's own demand-driven pursuit of the first products to experience economic connotation. Second, pay attention to the humanistic and emotional characteristics. With the advancement of material civilization, emotional needs of consumers in increasing the proportion of experience in product development enterprises are also increasingly attach importance to the use of the principles of humanism, the emphasis on product quality, while more attention to those who meet consumer psychology demand and can cause emotional resonance products. Again, non-substantive exchange of products. In the traditional economy, the principle of exchange from barter exchange value to use as the value of the currency exchange media are exchanging goods and services, and experience exchange economy is no longer in exchange for goods and traditional sense services, but in exchange feelings, happiness, experience and performance of non-use value of its physical, experience the product to the consumer is also pursuing a memorable and pleasant memories of the process.

Fourth, the experience value and feelings of uncertainty. Experience emphasized that the changes that occur customer psychology, different scenarios (events, objects or the environment, etc.) have different feelings, different experiences, different values, different customers have different experience feelings too.

\section{Experience Features two sports performance industry - customer participation}

Customer participation is that consumers can participate in organized sports performances throughout, the performances go, and you can only watch sports performance results. Creating and performing both in the whole process of performing experience, or experience the fruits of sports performance; customers have a larger initiative to actively participate in. It is this experience generated. Customers participating in sports performance characteristics of the industry are mainly involved in mental, physical and emotional participation.

Intellectual participation. Refers to consumers organizers of knowledge, information resources and sports performances, performers and related units exchanges and cooperation. Organizer or organizers should fully mobilize the intellectual participation of customers, even if the consumer has been talk and certainly intellectually but also improve their quality of service.

Physical participation. A course of conduct means customers personally involved in sports performances creators and performers all over every sports performance should be based on individual consumers as an unit, for customers to create an unique depth of experience program, with full respect for customers throughout the course of the service quality. Programs designed for different types of customers should be treated differently, such as experience the way of children, adolescents, adults, and the elderly should not be generalized.

Emotional engagement. It is a course of action. Refers to the customer to participate in sports performance project record times and performance, each of the sports performances should be based on individual consumer units. Customers enjoy high-quality entertainment services after sports 
performances will be voluntary wonderful experience itself is passed around to friends and family, to help other customers to actively participate in the mobilization of the whole show of activities.

\section{Experience "experience products" under the economic concept design ideas sports performance industry}

Minority traditional sports performances, literally three adjectives, are minorities, traditional sports and performances, which represents the folklore, as well as the perception of sports in the United States in these three areas. Experience the economic concept of sports performance industry experience product should integrate a variety of sensory stimuli, the impact of tourists to the full range of vision, hearing, smell, taste and touch, making them an unforgettable experience differences in culture and environment of the impression. By consumer participation and participation, sports performance industry experience in product design ideas can be build from these four aspects of experience entertainment experience, educational experience, aesthetic experience and escapist.

Entertainment experience. Experience the fundamental task of the economic philosophy is to enhance sports performance industry people's health, so that consumers will be multi-sensory experience differences, experience joy, so that customers get to enjoy the spirit involved in the process and get healthy. With the accelerated pace of life , the expansion of urbanization, more and more people want to get in his spare time to relax physically and mentally, to get back to life as a major motivation for the initiative and confidence of the people to participate in sports and recreational activities.

Educational Experience. Refers to customers through experiential activities can gain new knowledge and skills. And entertainment experience is different, educational experience includes the customer more actively involved. Performances in sports activities let the customer at the event to learn new knowledge and improve their skills in certain areas. Educational experience designed to enhance the customer experience of active participation in the activities of enthusiasm, spontaneously develop physical fitness and entertainment habits.

Aesthetic experience. Refers to this experience, each person immersed in a particular thing or the environment, while they rarely have an impact on things or the environment. Sports Performance Industry Experience Economy under the concept should take into account the psychological characteristics of consumers, in the aspects of design experience, experience the way of choice, creating an atmosphere to experience other aspects of the environment, must strive to make the customer experience the wonderful feeling.

Escapist experience. Not only is the customer completely immersed in activities to experience in sports performance, but also actively participate in the process of creating this experience to go to achieve escape the hustle and bustle and get rid of earthly purpose. To get the pleasure of mankind, which is a means to dedicate themselves to certain things into their own. Sports perform for people to be able to create such an environment for people to forget their troubles in the exercise, away from all the pressure, and thus threw him into the experience to go.

\section{Multidimensional factor analysis of Restricts sports performance industry development in Sichuan minority rural areas}

Economic development lags behind in Sichuan Province national minority rural area. Due to the remoteness of Sichuan minority areas, inaccessible, economically backward, traditional national sports organization and management mechanism is quite lag, lack of investment, lack of talent, it is difficult for traditional national sports conducted in-depth research and development, resulting national traditional sports activities organized fewer, traditional sports activities, not many, even in the few venues where their activities facilities are relatively old. Minority areas in Sichuan, and even the national traditional sports in the cold, modern sport has failed to really integrate minorities' ethnic people living among the embarrassing situation. Impact of the emerging sports performances of traditional national sports performances. Modern sports not only formed a theoretical system, and 
can make full use of television, computers and other high-tech media, allowing more and more people to accept, and then embarked on the sports market and diversified industrial development, and the potential huge, full of vitality. Meanwhile, universal education makes modern popular sports, such as gymnastics, basketball, table tennis and other widely into various regions of Sichuan and rural schools, occupies a leading position among young people, the traditional sports games although always liked by the kids, but never landed on the school's humble coupled with weak minority of Sichuan sports competition, difficult to incorporate into the regular game, cause it difficult to promote, and gradually marginalized position. Backward mode of inheritance. Minority Traditional Sports Culture in Sichuan mainly uses "words and deeds" of this ancient tradition way, that festivals, celebrations, meetings and other group activities for the media, be passionate singing and dancing performances, traditional sports to make the national heritage and development. Although this form enrich people's cultural life, with a strong cultural entertainment, but heritage point of view, neither the formation of the system of channels, and no use of modern high-tech means of inheritance, it is difficult to be theoretically summary. Relative lack of theoretical research. Hysteresis limits the development of theoretical research Minority Traditional Sports of the founding of New China, the theory of the evolution of traditional national sports development stage and gradually into organized, published a series of research monographs, Sichuan minority sports, states are under the State Sports Commission led wrote sports blogs, theoretical studies and achieved some success. However difficult to find, the scientific research on the overall national traditional sports are also at a low level, the theory is not yet national sports system, is not comprehensive, holistic study of the lack of Minority Traditional Sports. In addition, publicity, lack of organization and sports instructors, the lack of venues has also become a factor restricting the development of national sports.

\section{Minority Sports Performance Industry Sustainable Development}

Reference model of intangible cultural heritage protection and inheritance. "Experience Economy" theory has been applied in the development and promotion of sports performance industry, in the modern metropolis developed to developed service economy is the economic basis for large-scale experience, is in full swing, but in rural areas, especially in underdeveloped rural areas in Sichuan Province minorities, people's material life under stressful conditions, to explore its traditional non- material culture, forming a unique sports performance industry to promote local economic development. In fact, the key point of minority sports intangible cultural heritage protection is "the spiritual core of culture", "cultural space" and "cultural heritage." One is to go out, the diversity of intangible cultural heritage of minority sports "spiritual core" as a tourism marketing highlights carried unbounded spread, and this is an effective way to promote cultural exchange and cultural self-confidence. The second is through the "introduction" minority villages of tourism development, promotion of cultural heritage in a particular space, "discriminating" tourists "unbounded" of diverse ethnic minorities to participate in sport to experience the original cultural environment. Therefore, you should continue to adhere to the premise of the rich "three key points" in the form of intangible cultural heritage of minority sports diversity was likely to sustainable use.

The joint development of Sichuan Province with rich tourism resources. Tourism is the people leave the usual environment to other places to seek some kind of "extraordinary" events of an experience, the essential attribute of tourism lies in the difference in the experience of spiritual enjoyment. Both from the demand point of view or from the supply promote tourism experience, in-depth travel conditions are ripe. In rural areas rich in tourism resources in western Sichuan minority, drawing on the depth of experience to promote tourism and the development of personalized, participatory, theme-based experience economy, make full use of national sports features performances and related national and ethnic costumes and other memorabilia to develop sports performance industry, the tourism, vacation, customs and other organic together, constitute a wide range of national sports tourism resources, so that tourists themselves into" taking place in the past," to experience different cultures in real life. I believe in the near future, sports performance industry in rural areas of Sichuan Province minorities will become an effective way for new rural 
areas of Minority Economic Development and new rural construction, but also the poor western regions, or the best advantage of the dominant economic sector.

Interaction with the development of new rural construction in Sichuan Province. Many rural ethnic minority areas in Sichuan and Sichuan minority traditional sports culture has a broad mass base, by the peasant masses love, there is great room for development. It facilitates the exchange of neighbors, in line with the needs of farmers and promotes agricultural production. Therefore, we should give full play to the interaction between minority traditional sports culture and the construction of new socialist countryside. With the development of market economy and the tourism industry in Sichuan, People's Traditional Ethnic Sports Culture increasing emphasis on the development and use of building new countryside in Sichuan it will play a significant role in promoting. On the other hand, building a new socialist countryside will promote the continuation and development of Sichuan minority traditional sports culture, to provide space for the survival and development. Therefore, we should proceed from reality in ethnic minority areas in Sichuan, and embark on a path of development characteristics in line with the situation in the province, both for traditional Sichuan minority sports culture to promote the new rural construction, and so in turn promote the new rural construction in Sichuan Minority Traditional Sports cultural heritage and development.

Earthquake reconstruction with an opportunity to strengthen the construction of sports and cultural minority neighborhoods. Sichuan province's 14 ethnic groups in order Kawanishi Ah, sweet, cool-based funeral, Qiang, Yi most representative and typical . In the "5.12 Wenchuan Earthquake" in both Tibetan and Qiang neighborhoods suffered heavy losses. Especially Qiang, earthquake about 20,000 people dead or missing, about $10 \%$ of the total population Qiang, including a large number of ethnic and cultural minorities name holders. After the earthquake, the State Department has issued a number of disasters -related policies and regulations concerning the protection of national culture, deeply affected ethnic ghettos, fully tap the local national sports culture. Reconstruction, rescue Qiang traditional sports culture, how to inherit and develop minority sports culture has been unprecedented attention. Thus, minority sports performance industry in rural areas of reconstruction can take the express train to fully tap the cultural characteristics of ethnic minorities and ethnic dances and performances of ethnic customs with the elements of the integration into the modern sports hold some groups of activities performed, subtle manipulation audience, performers and even nearby residents Qiang became a member of sports and cultural heritage, which is a new road for Ethnic Minorities future sports performance industry.

\section{Acknowledgements}

The research work was supported by Rural Development Research Center of Sichuan Province under Grant No. CR1218 and Sichuan Provincial Key Research Base-- The Research Center of Leisure Sports Industry Development under Grant No. XXTYCY2014C05.

\section{References}

[1] Z. Chang, D.H. Guo. Study on the Changes of Chinese minority sports and the sustainable development of Guizhou national minority sports. Guizhou Ethnic Studies, 2011, 32(6):162-166.

[2] Y. Wang. The study on Selection and cultivation of our countries' regional advantageous sports. Shanghai Sport University, 2011.

[3]L.X. Tang, Z.L. Cai and Y. Liu. The plight and Path Choice of China's traditional national sports development. Xi'an Sport University, 2011, 28(5):577-578.

[4] X.Y. Jiang. The comparative analysis of economic experience and non economic experience. Chinese Industrial Economy. 2003, 9 . 